\title{
Gastroprotective Effect of Freeze Dried Stripped Snakehead Fish (Channa striata Bloch.) Aqueous Extract against Aspirin Induced Ulcerogenesis in Pylorus Ligated Rats
}

\author{
Mohammed Safwan Ali Khan, ${ }^{1,2}$ Abdul Manan Mat Jais, ${ }^{1}$ Javeed Hussain, ${ }^{2}$ Faiza Siddiqua, \\ A. Gopala Reddy, ${ }^{3}$ P. Shivakumar, ${ }^{3}$ and D. Madhuri ${ }^{4}$ \\ ${ }^{1}$ Pharmacology \& Toxicology Laboratory, Department of Biomedical Sciences, Faculty of Medicine and Health Sciences, \\ University Putra Malaysia, 43400 Serdang, Selangor Darul Ehsan, Malaysia \\ ${ }^{2}$ Natural Products Research Laboratory and Department of Pharmacology, Anwarul Uloom College of Pharmacy, \\ New Mallepally, Hyderabad, Andhra Pradesh 500 001, India \\ ${ }^{3}$ Department of Pharmacology \& Toxicology, College of Veterinary Science, Acharya N.G. Ranga Agricultural University, \\ Rajendra Nagar, Hyderabad, Andhra Pradesh 500 030, India \\ ${ }^{4}$ Department of Pathology, College of Veterinary Science, Acharya N.G. Ranga Agricultural University, Rajendra Nagar, \\ Hyderabad, Andhra Pradesh 500 030, India
}

Correspondence should be addressed to Mohammed Safwan Ali Khan; safwanpharma@gmail.com

Received 8 January 2014; Accepted 2 March 2014; Published 29 May 2014

Academic Editors: H. Cerecetto, V. Manju, and S. Mingmalairak

Copyright (C) 2014 Mohammed Safwan Ali Khan et al. This is an open access article distributed under the Creative Commons Attribution License, which permits unrestricted use, distribution, and reproduction in any medium, provided the original work is properly cited.

Channa striata (Bloch.) is a fresh water fish belonging to the family Channidae. The stripped snakehead fish possesses wide range of medicinal properties. In view of traditional use of $C$. striata for wound healing, the present study was undertaken to investigate the beneficial effects of orally administered freeze dried aqueous extract of Channa striata (AECS) in experimentally induced gastric ulcers in Wistar rats. Aspirin induced ulcerogenesis in pyloric ligation model was used for the assessment of antiulcer activity and Ranitidine $(50 \mathrm{mg} / \mathrm{kg}$ ) was employed as the standard drug. The various gastric parameters like volume of gastric juice, $\mathrm{pH}$, free and total acidities, ulcer index, and levels of antioxidant enzymes like catalase, superoxide dismutase, and lipid peroxidation marker malondialdehyde were determined. AECS at concentrations of $40 \%$ and $50 \% \mathrm{w} / \mathrm{v}$ significantly decreased the volume of gastric juice and increased the levels of catalase while considerable decrease in free and total acidities and increase in superoxide dismutase were observed with the treatment of standard drug and AECS (50\% w/v). All the test doses of AECS markedly decreased ulcer index and malondialdehyde compared to the standard drug whereas AECS 30\% w/v did not alter volume of gastric juice, $\mathrm{pH}$, free and total acidities, catalase, and superoxide dismutase. From these findings, it can be concluded that AECS is devoid of acid neutralizing effects at lower doses and possesses antisecretory and antiulcer activities and this could be related to its antioxidant mechanism.

\section{Introduction}

Channa striata (Bloch.) is commonly known as stripped snakehead fish and Haruan in Malay. C. striata is indigenous to Malaysia. It is a tropical and air breathing carnivorous freshwater fish from the family Channidae. There are all together 30 species in the family reported around the world and eight of them are found in Malaysia. Members of the family are also found in all ASEAN countries, namely,
Myanmar, Thailand, Laos, Cambodia, Vietnam, Brunei, Philippines, Indonesia, and Singapore [1]. C. striata is wild species found in small rivers, lakes, pools, and shallow water bodies and in its natural habitat. It can survive in harsh environments with low dissolved oxygen and high ammonia [2]. C. striata contains all the essential amino and fatty acids required for wound healing $[3,4]$; the fatty acid content of this fish is rich in arachidonic acid (ARA) [5]. Mohd Shafri and Mat Jais reviewed in detail the description, habitat, traditional 
therapeutic uses, chemical composition, and scientifically proven medicinal properties [6]. The fish is reported to possess antinociceptive $[7,8]$, antipyretic [9], antidepressant $[10,11]$, anti-inflammatory [12], antifungal [13], antimicrobial [14], antiosteoarthritic [15], neuroregenerative, and restorative [16] properties and enhances wound healing process [1719]. In view of traditional and scientific reports on wound healing potential of C. striata and presence of wide range of bioactive components, the present study was undertaken to investigate antiulcer activity.

\section{Material and Methods}

2.1. Preparation of Aqueous Extract of Channa striata (Bloch.) and Freeze Drying. Adult Channa striata (Bloch.) of medium size (total length of fish $20.60-44.10 \mathrm{~cm}$ ), weighing 250 $400 \mathrm{~g} / \mathrm{fish}$, were collected in November 2011 from Kuala Terengganu, Terengganu District (N $5^{\circ} 19^{\prime} 29.40^{\prime \prime}$ and E $103^{\circ} 08^{\prime} 27.29^{\prime \prime}$ ) from Peninsular Malaysia. The temperature was $28-33^{\circ} \mathrm{C}$ with $\mathrm{pH}$ between 5.60 and 8.20 , salinity $0 \mathrm{ppt}$, dissolved oxygen in the range of $2.00-11.00 \mathrm{mg} / \mathrm{L}$, turbidity in the range of $1.00-18.00 \mathrm{NTU}$, and conductivity 0.54 $0.55 \mathrm{mS} / \mathrm{cm}$. The fishes were verified by Terengganu Fisheries Department, Ministry of Agriculture, Malaysia. Fillets were obtained by carefully cutting the fish lengthwise along backbone to gain maximum amount of flesh. The whole fish fillet extract was prepared by using pressure cooker set at $100^{\circ} \mathrm{C}$ for $30 \mathrm{~min}$. The fresh boneless fillet was weighed and placed on a stainless steel wire mesh mounted on a stainless steel tripod in the pressure cooker. Fish fillet and distilled water were added in volume ratio of $1: 2$. The extract was obtained through steaming. At the end of the extraction procedure, the fillet was discarded while collecting the liquid extract using Whatman no. 1 filter paper. The obtained extract was freeze dried using a freeze drier and stored at $20^{\circ} \mathrm{C}$ until use $[7,8]$.

2.2. Drugs and Chemicals. Chloroform AR, phenolphthalein $\mathrm{pH}$ indicator solution, and sodium hydroxide pellets were procured from SD Fine-Chem Limited, Mumbai, while pure aspirin was obtained from Divis Laboratories, Hyderabad. Ranitidine (as Rantac $150 \mathrm{mg}$ ) was from J.B Chemicals and Pharmaceuticals, Mumbai, while surgical spirit was obtained from Kakatiya Pharma, Hyderabad. Topfer's reagent and distilled water were obtained from Nice Chemicals, China, and Stangen Fine Chemicals, Hyderabad, respectively. All chemicals were used without further purification.

2.3. Animals. For the evaluation of the antiulcer property, male albino Wistar rats weighing 160-200g were used. The study was conducted after the approval of protocol by Institutional Animal Ethical Committee (IAEC). The animals were maintained under standard conditions, that is, housed in polypropylene cages and maintained at a temperature $27 \pm 2^{\circ} \mathrm{C}$, relative humidity $65 \pm 10 \%$ under 12 -hour light and dark cycle. The animals were fed with standard pellet diet with water ad libitum in an animal house (Reg. number 1534/PO/a/11/CPCSEA) approved by the Committee for the Purpose of Control and Supervision on Experimental Animals (CPCSEA). The animals were acclimatized for ten days under laboratory conditions before carrying out the experiments.

2.4. Acute Toxicity and Selection of Test Doses. Earlier investigations indicate that Channa striata (Bloch.) aqueous extract is safe and nontoxic even at the dose of $8 \mathrm{~g} / \mathrm{kg}$ or $100 \% \mathrm{w} / \mathrm{v}$ concentration $[7,8]$. Doses of $30 \%, 40 \%$, and $50 \% \mathrm{w} / \mathrm{v}$ were selected for the screening of antiulcer activity based on the report of Saleem et al. [10].

\subsection{Evaluation of Antiulcer Activity}

2.5.1. Aspirin Induced Ulcerogenesis in Pylorus Ligated Rats. Aspirin induced ulcerogenesis in pylorus ligated rats model was used for the evaluation of antiulcer activity with slight modification. The animals were divided into five groups $(n=$ 6). Group I served as negative control and received only vehicle. Groups II, III, and IV received aqueous extract of Channa striata (AECS) at 30\%, $40 \%$, and $50 \% \mathrm{w} / \mathrm{v}$ concentrations, respectively, orally at the volume of $10 \mathrm{~mL} / \mathrm{kg}$. Group V served as standard and was treated with standard drug (Ranitidine $50 \mathrm{mg} / \mathrm{kg}$, p.o) [20]. Aspirin suspended in $1 \%$ CMC in water was administered orally at a dose of $500 \mathrm{mg} / \mathrm{kg}$ in 12 -hour fasted rats [21]. The test extract and standard drug treatment were done $30 \mathrm{~min}$ prior to the administration of aspirin. After $30 \mathrm{~min}$, the pyloric ligation surgery was performed. Four hours later, the animals were sacrificed by euthanasia.

Collection and Measurement of Gastric Juice. The stomachs were excised carefully keeping the esophagus closed. The stomachs were opened along the greater curvature, removing the luminal contents. The gastric contents were collected and centrifuged at $1000 \mathrm{rpm}$ for 10 minutes. After centrifugation samples were decanted and the volume of gastric juice was noted and is expressed as $\mathrm{mL} / 100 \mathrm{~g}$ body weight. The contents were subjected to analysis for free and total acidities.

Determination of Gastric Juice pH. One $\mathrm{mL}$ of supernatant liquid was diluted to $10 \mathrm{~mL}$ with distilled water. The $\mathrm{pH}$ of the solution was recorded with the help of digital $\mathrm{pH}$ meter.

Estimation of Total and Free Acidities. The above solution was titrated against $0.01 \mathrm{~N} \mathrm{NaOH}$ using Topfer's reagent as indicator. The endpoint of the titration was when the solution turns orange in colour. The volume of $\mathrm{NaOH}$ was noted which corresponds to the free acidity. Further the titration was continued till the solution regained pink colour. The total volume of $\mathrm{NaOH}$ was noted, which corresponds to total acidity.

Determination of Ulcer Index. Mean ulcer score for each animal is expressed as ulcer index. The stomachs were washed with running water to see the ulcers in the glandular portion of the stomach. The number of ulcers per stomach was noted and the severity of the ulcers was scored microscopically with 
the help of hand lens (10x) and scoring was done as per Asru [22]:

$$
\begin{aligned}
& 0=\text { Normal stomach } \\
& 0.5=\text { Red coloration } \\
& 1=\text { Spot ulcers } \\
& 1.5=\text { Haemorrhagic streaks } \\
& 2=\text { Ulcers }>3 \mathrm{~mm} \text { but }<5 \mathrm{~mm} \\
& 3=\text { Ulcers }>5 \mathrm{~mm} .
\end{aligned}
$$

The percentage of protection was calculated by the formula

$$
\text { Percentage protection }=100-\left(\frac{\mathrm{Ut}}{\mathrm{Uc}} \times 100\right) \text {, }
$$

where $\mathrm{Ut}=$ ulcer index of the treated group and $\mathrm{Uc}=$ ulcer index of control group.

Assessment of Oxidative Damage in Gastric Tissue. After measuring the ulcer index, the stomachs were washed with $0.9 \%(\mathrm{w} / \mathrm{v}) \mathrm{NaCl}$, cut into small pieces, and homogenized with a glass homogenizer in ice-cold $0.15 \mathrm{M} \mathrm{KCl}$ solution to produce a $20 \%(\mathrm{w} / \mathrm{v})$ homogenate. The homogenate was used for the determination of various biochemical parameters.

(1) Estimation of Catalase. Catalase containing sample is allowed to split $\mathrm{H}_{2} \mathrm{O}_{2}$ followed by adding dichromate/acetic acid mixture to stop the reaction. Dichromate in acetic acid is reduced first to unstable blue colored perchromic acid and finally to stable green colored chromic acetate in the presence of $\mathrm{H}_{2} \mathrm{O}_{2}$, which is measured colorimetrically at $570 \mathrm{~nm}$. Thus chromic acetate measured gives the amount of freely available $\mathrm{H}_{2} \mathrm{O}_{2}$. To assay mixture containing $0.4 \mathrm{~mL}$ of $0.2 \mathrm{M} \mathrm{H}_{2} \mathrm{O}_{2}$ and $0.5 \mathrm{~mL}$ of $0.01 \mathrm{M}$ phosphate buffer $(\mathrm{pH} 7), 0.1 \mathrm{~mL}$ of homogenate was added and mixed well. Into this, $2 \mathrm{~mL}$ of dichromate acetic acid solution was blown exactly after 1 min and kept in boiling water bath for $10 \mathrm{~min}$. The absorbance of green colored chromic acetate formed was measured at $570 \mathrm{~nm}$ against reagent blank containing $0.4 \mathrm{~mL}$ of $0.2 \mathrm{M}$ $\mathrm{H}_{2} \mathrm{O}_{2}$ and $0.5 \mathrm{~mL}$ of $0.01 \mathrm{M}$ phosphate buffer ( $\left.\mathrm{pH} 7\right)$. The enzyme level is expressed as units/mg of tissue [23].

(2) Estimation of Superoxide Dismutase. The reaction involves generation of superoxide by pyrogallol auto-oxidation and the inhibition of superoxide dependent reduction of the tetrazolium dye MTT [3-(4-5 dimethyl thiazol 2-yl) 2,5diphenyl tetrazolium bromide] to its formazan. The reaction is terminated by the addition of dimethyl sulfoxide (DMSO), which helps to solubilize the formazan formed. The color evolved is stable for many hours and is expressed as SOD units (one unit of SOD is the amount in $\mathrm{mg}$ of protein required to inhibit the MTT reduction by 50\%). The reagents were added in the sample, control, and the blank as shown in Table 1.

The absorbance was read at $570 \mathrm{~nm}$ against distilled water (blank). Superoxide dismutase was expressed as SOD units/mg of tissue [24].

(3) Estimation of Malondialdehyde. Malondialdehyde, formed from the breakdown of polyunsaturated fatty acids, serves as
TABLE 1: Details of various reagents and their quantities added to sample, control, and blank during the estimation of superoxide dismutase.

\begin{tabular}{lccc}
\hline Reagents & Sample & Control & $\begin{array}{c}\text { Blank } \\
\text { (duplicate) }\end{array}$ \\
\hline PBS & $0.65 \mathrm{~mL}$ & $0.65 \mathrm{~mL}$ & $0.65 \mathrm{~mL}$ \\
MTT & $30 \mu \mathrm{L}$ & $30 \mu \mathrm{L}$ & $30 \mu \mathrm{L}$ \\
Homogenate & $10 \mu \mathrm{L}$ & - & - \\
Pyrogallol & $75 \mu \mathrm{L}$ & $75 \mu \mathrm{L}$ & $75 \mu \mathrm{L}$ \\
\hline
\end{tabular}

The sample, control, and blank were incubated for $5 \mathrm{~min}$ at room temperature

$\begin{array}{llll}\text { DMSO } & 0.75 & 0.75 & 0.75\end{array}$

a convenient index for determining the extent of peroxidation reaction. Malondialdehyde has been identified as the product of lipid peroxidation that reacts with thiobarbituric acid to give a red colour absorbing light maximally at $535 \mathrm{~nm}$. One $\mathrm{g}$ of tissue sample with $10 \mathrm{~mL}$ of $0.2 \mathrm{M}$ Tris $\mathrm{HCl}$ buffer ( $\mathrm{pH}$ 7.2) was taken in a tissue homogenizer to get a $10 \%$ homogenate. $500 \mu \mathrm{L}$ of supernatant from the homogenate, $1 \mathrm{~mL}$ of $10 \%$ trichloroacetic acid, and $1 \mathrm{~mL}$ of $0.67 \%$ thiobarbituric acid were taken in a tightly stoppered tube. The tube was heated to boiling temperature for $45 \mathrm{~min}$. After cooling the tube, the contents were centrifuged. The supernatant was read at $532 \mathrm{~nm}$ against blank. The concentration of test samples was obtained using molar extinction coefficient of MDA. The amount of MDA is expressed as number of moles of MDA/mg of tissue [25].

2.6. Statistical Analysis. Data obtained was analyzed by oneway ANOVA followed by Dunnett's multiple comparisons post hoc test using Graphpad Prism version 4.0, 32 bits for windows, Graphpad software, San Diego, California, USA (http://www.graphpad.com/). The values are expressed as mean \pm standard error of mean (SEM). $P<0.05$ was considered statistically significant.

\section{Results}

\subsection{Results of Aspirin Induced Ulcerogenesis in Pylorus Ligated Rats (Figure 2 and Table 2).}

3.1.1. Volume of Gastric Juice. AECS significantly $(P<0.05)$ decreased the volume of gastric juice at the dose of $40 \% \mathrm{w} / \mathrm{v}$ concentration. Further decrease in the output of gastric juice was observed with the treatment of higher concentration, that is, $50 \% \mathrm{w} / \mathrm{v}(P<0.01)$. However, the least test dose $(30 \% \mathrm{w} / \mathrm{v})$ used in the study did not show any significant antisecretory effect (as shown in Figure 2 and Table 2).

3.1.2. pH of Gastric Juice. Treatment with the standard drug (Ranitidine $50 \mathrm{mg} / \mathrm{kg})$ significantly $(P<0.01)$ raised the $\mathrm{pH}$ from $3.83 \pm 0.10$ (negative control) to $4.95 \pm 0.16$, while all the concentrations of AECS failed to elevate $\mathrm{pH}$ of the gastric juice (as shown in Figure 2 and Table 2). 
TABLE 2: Results of aspirin induced ulcerogenesis in pyloric ligation model.

\begin{tabular}{|c|c|c|c|c|c|}
\hline \multirow{3}{*}{ Parameters } & \multicolumn{5}{|c|}{ Various groups } \\
\hline & \multirow{2}{*}{ Negative control } & \multirow{2}{*}{$\begin{array}{c}\text { Ranitidine } \\
50 \mathrm{mg} / \mathrm{kg}\end{array}$} & \multicolumn{3}{|c|}{ Aqueous extract of Channa striata } \\
\hline & & & $30 \% \mathrm{w} / \mathrm{v}$ & $40 \% \mathrm{w} / \mathrm{v}$ & $50 \% \mathrm{w} / \mathrm{v}$ \\
\hline Volume of gastric juice $(\mathrm{mL})$ & $5.43 \pm 0.22$ & $4.36 \pm 0.17^{* *}$ & $5.26 \pm 0.16^{\mathrm{ns}}$ & $4.53 \pm 0.16^{*}$ & $4.23 \pm 0.32^{* *}$ \\
\hline $\mathrm{pH}$ & $3.83 \pm 0.108$ & $4.95 \pm 0.16^{* *}$ & $3.33 \pm 0.33^{\mathrm{ns}}$ & $3.68 \pm 0.18^{\mathrm{ns}}$ & $3.65 \pm 0.084^{\mathrm{ns}}$ \\
\hline Free acidity & $51.00 \pm 2.85$ & $40.00 \pm 2.47^{*}$ & $45.00 \pm 2.72^{\mathrm{ns}}$ & $44.00 \pm 1.59^{\mathrm{ns}}$ & $39.33 \pm 2.97^{*}$ \\
\hline Total acidity & $93.17 \pm 1.86$ & $85.50 \pm 1.40^{* *}$ & $90.50 \pm 1.72^{\mathrm{ns}}$ & $90.17 \pm 1.74^{\mathrm{ns}}$ & $86.67 \pm 1.20^{*}$ \\
\hline Ulcer index & $5.91 \pm 0.45$ & $2.75 \pm 0.38^{* * *}$ & $4.00 \pm 0.36^{* *}$ & $3.75 \pm 0.38^{* *}$ & $3.08 \pm 0.35^{* * *}$ \\
\hline Percentage of inhibition & - & $53.46 \%$ & $32.31 \%$ & $36.54 \%$ & $47.88 \%$ \\
\hline Catalase (units/mg of tissue) & $0.011 \pm 0.011$ & $0.059 \pm 0.0032^{* *}$ & $0.041 \pm 0.0079^{\mathrm{ns}}$ & $0.066 \pm 0.0064^{* *}$ & $0.072 \pm 0.012^{* * *}$ \\
\hline Superoxide dismutase (units/mg of tissue) & $0.015 \pm 0.010$ & $0.071 \pm 0.0094^{* *}$ & $0.027 \pm 0.0050^{\mathrm{ns}}$ & $0.047 \pm 0.012^{\mathrm{ns}}$ & $0.055 \pm 0.013^{*}$ \\
\hline Malondialdehyde (moles/mg of tissue) & $0.190 \pm 0.0012$ & $0.089 \pm 0.0013^{* * *}$ & $0.088 \pm 0.0034^{* * *}$ & $0.085 \pm 0.0078^{* * *}$ & $0.072 \pm 0.013^{* * *}$ \\
\hline
\end{tabular}

Note: sample size $(n)=6$ rats per group. Data is expressed as mean \pm standard error of mean and standard deviation in parenthesis. ${ }^{*} P<0.05,{ }^{* *} P<0.01$,

${ }^{* * *} P<0.001$ and ns nonsignificant versus negative control (on statistical analysis with ANOVA, followed by Dunnett's multiple comparison post hoc test).

3.1.3. Free and Total Acidities. Likewise $30 \%$ and $40 \% \mathrm{w} / \mathrm{v}$ solutions of AECS did not alter free and total acidities. A slight $(P<0.05)$ decrease in free and total acidities was observed with the treatment of 50\% w/v AECS solution against the significant decrease in free and total acidities by the standard drug with $P<0.01$ and $P<0.001$, respectively (as shown in Figure 2 and Table 2).

3.1.4. Ulcer Index (UI). All the test doses of AECS solutions $(30 \%, 40 \%$, and $50 \% \mathrm{w} / \mathrm{v})$ significantly decreased the ulcer index ( $P$ value ranging from 0.01 to 0.001 ). The decrease in ulcer index in the AECS (50\% w/v) treated group is comparable with that of the standard drug. A dose related increase in percentage protection was observed. The percentage of inhibition for $40 \%$ and 50\% AECS was found to be $36.54 \%$ and $47.88 \%$, respectively, while the standard showed $53.46 \%$ (as shown in Figure 2 and Table 2).

3.1.5. Catalase (CAT). A dose dependent increase was noticed with the treatment of AECS with $P$ value ranging from 0.01 to 0.001 , except the lowest test dose used in the experiment. The results of standard and $40 \% \mathrm{w} / \mathrm{v}$ AECS were found to be similar, while 50\% AECS exhibited maximum increase in the level of CAT with $P<0.001$ (as shown in Figure 2 and Table 2).

3.1.6. Superoxide Dismutase (SOD). AECS at $30 \%$ and $40 \%$ $\mathrm{w} / \mathrm{v}$ concentrations did not cause significant increase in the level of superoxide dismutase whilst $50 \% \mathrm{w} / \mathrm{v}$ AECS raised the level of SOD with $P<0.05$. The treatment with the standard displayed the most significant rise with $P<0.01$ (as shown in Figure 2 and Table 2).

3.1.7. Malondialdehyde (MDA). The standard drug and all the test doses of AECS significantly decreased the formation of malondialdehyde, an end product of lipid peroxidation. A potent as well as consistent decrease in the level of MDA $(P<0.001)$ was observed. The decrease in MDA was proportionate to the increasing test doses; further the effect of all the concentrations of AECS was more profound than the standard. This highlights the gastroprotective potential of AECS against lipid peroxidation of gastric mucosa. The results are displayed in Figure 2 and Table 2.

\subsubsection{Macroscopy of Stomachs}

(a) Negative Control. The stomach shows red coloration, haemorrhage, hyperaemia, one spot ulcer, two ulcers with diameter in range of $3-5 \mathrm{~mm}$, and two ulcers greater than $5 \mathrm{~mm}$.

(b) AECS $(30 \% w / v)$. Red coloration and four spot ulcers are seen in the stomach.

(c) AECS $(40 \% w / v)$. The stomach coloration is normal but shows two spot ulcers.

(d) AECS $(50 \% w / v)$. Erythema, an inflammatory sign, can be observed in the stomach with complete absence of ulcers.

(e) Standard. The stomach reveals partial red coloration with no ulcers. The images are shown in Figure 1.

\section{Discussion}

Channa striata contains unsaturated fatty acids (UFA) and essential amino acids (AA) that stimulate and promote healing of wounds $[3,18,19,26]$. C. striata contains alanine, arginine, aspartic acid, glutamic acid, glycine, leucine, and proline [27]. An earlier report of Gam et al. reported lysine, threonine, and valine as the other most abundant amino acids in C. striata [28]. Some of these amino acids are the integral components of gastric mucous [29]. Furthermore some of these amino acids are known to have significant antioxidant properties particularly with linoleic acid [30].

C. striata fresh fillet also contains high amount of glycine which is one of the important components responsible for the formation of collagen in the various tissues of human body [ 3 , 27, 31]. C. striata treatment promotes remodeling of collagen through the synthesis of inter- and intramolecular protein 


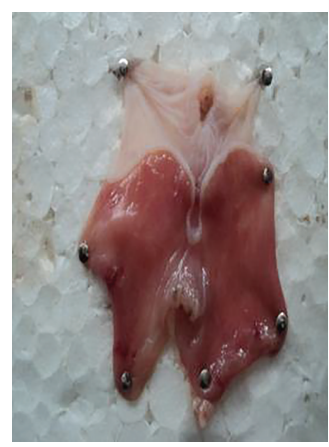

(a)

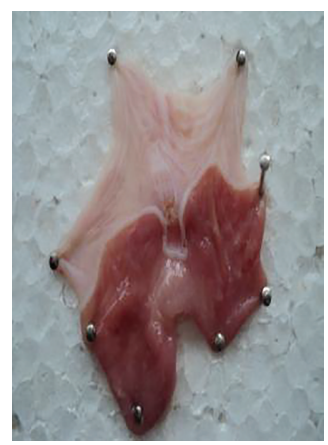

(b)

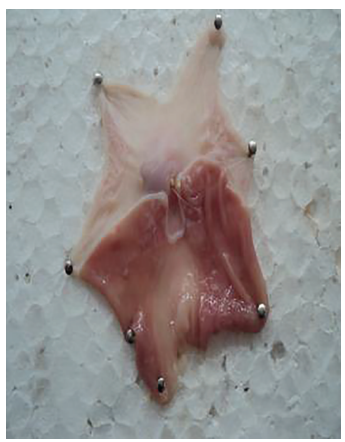

(c)

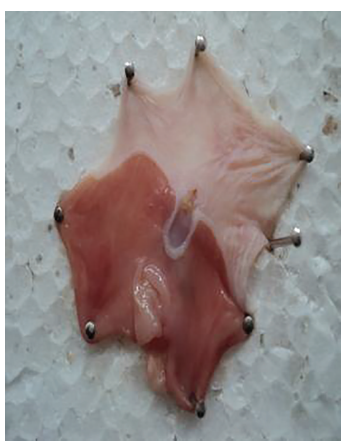

(d)

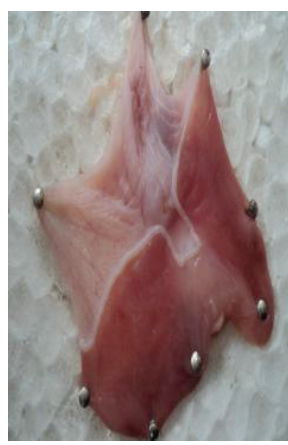

(e)

Figure 1: Photos of rat's stomachs subjected to aspirin induced ulcerogenesis in pyloric ligation model. Note: (a) negative control; (b) Test-I (AECS 30\% w/v); (c) Test-II (AECS 40\% w/v); (d) Test-III (AECS 50\% w/v); and (e) standard (Ranitidine $50 \mathrm{mg} / \mathrm{kg}$ ).

cross-linking. This action strengthens the body tissues and prevents further degradation $[1,15]$. Glycine is the amino acid present in C. striata in the highest concentration. Glycine is important in healing process as it is one of the major components of human tissue collagen. It promotes tissue repair synergistically by forming a polypeptide with other essential amino acids like alanine, arginine, isoleucine, phenylalanine, proline, and serine [32].

Arginine plays critical and multiple roles in wound healing process. It stimulates the release of hormones like growth hormone from pituitary and insulin from pancreas [33]. In postinjury catabolic state, it decreases the urinary nitrogen loss to regulate nitrogen balance [34]. This amino acid is also a substrate for two integral enzymes - nitric oxide synthetase (NOS) and arginase. Arginine is metabolized in wounds by the action of enzyme arginase abundantly present in wound fluid [35]. Arginine produces hydroxyproline, an important component ( $9.1 \%$ of the total amino acid residue) of collagen [36]. Aspartic acid an excitatory amino acid that is involved in antioxidant mechanism is also found in high amount in C. striata [37].

The dominant fatty acids in C. striata are palmitic acid (C16: 0), stearic acid (C18: 0), oleic acid (C18: 1n-9), and linoleic acid (C18: 2n-6) [27]. Polyunsaturated fatty acids (PUFA) components (arachidonic and linoleic acids) of $C$. striata decrease serum cholesterol and triglycerides levels and inhibit clotting of blood [38]. This action can facilitate the supply of blood to the gastric tissue countering the obstruction, one of the etiological factors in the pathogenesis of peptic ulcers. Further, the report of Mat Jais et al. suggests the high compositions of fatty acids and certain amino acids as responsible agents for the healing effects of $C$. striata [3]. The oleic and stearic acids are reported to attenuate polymorphonuclear leukocytes activity and influence membrane fluidity, consequently suppressing inflammatory processes [27]. Arachidonic acid which is a precursor of prostaglandin is found in C. striata in considerable amounts. The prostaglandins play a major role in growth of tissue and wound healing [39-41].

Furthermore, Huang et al. have reported that arachidonylglycine (a lipoamino acid formed by the conjugation of arachidonic acid and glycine) suppresses edema and pain [42]. This can relieve or minimize the gastric distress that accompanies peptic ulceration. Vitamin-A (Retinol) an essential factor for wound healing is also present in high concentration in C. striata [3, 43].

C. striata extract has also demonstrated inhibitory effects on $\mathrm{H}$. pylori [44]. Besides promising results as an antibacterial and antifungal agent against certain strains, $C$. striata extracts exhibited antibacterial activity in various studies against wide range of bacteria like Staphylococcus aureus [13], Aeromonas hydrophila and Pseudomonas aeruginosa [14], Bacillus subtilis, Klebsiella pneumoniae, and Pseudomonas aeruginosa [45]. C. striata extracts also demonstrated antifungal activities against Aleurisma keratinophilum, Botrytis pyramidalis, Cordyceps militaris, Neurospora crassa, and Paecilomyces fumosoroseus [13].

The beneficial effects of aqueous extract of Channa striata (AECS) were observed at the higher test doses. The ineffectiveness of low dose of AECS $(30 \% \mathrm{w} / \mathrm{v})$ could be due to the presence of bioactive compounds in quantities lesser than the minimum effective dose. Therefore, there is a need for a similar study at higher concentrations to evaluate gastroprotective potential of AECS appropriately and justify the observations of the present investigation properly. $C$. striata is a nutraceutical agent and well tolerable even at the higher concentrations; the prospect of increasing the test doses in the future studies does exist. The test doses can be increased up to $100 \% \mathrm{w} / \mathrm{v}$ concentration [8] or $8 \mathrm{~g} / \mathrm{kg}$ [7] as used by them in their studies. Additionally, in view of report by Dahlan-Daud et al., [27] on the chemical composition of various fractions of C. striata, it is expected that a similar study using the other bioactive fractions like Haruan Commercial Essence and Lower Phase of Haruan Traditional Extract would give more meaningful results.

\section{Conclusion}

The present study reveals that AECS is devoid of gastric acid neutralizing effect but possesses potent antisecretory and antiulcer properties. The observed pharmacological action 


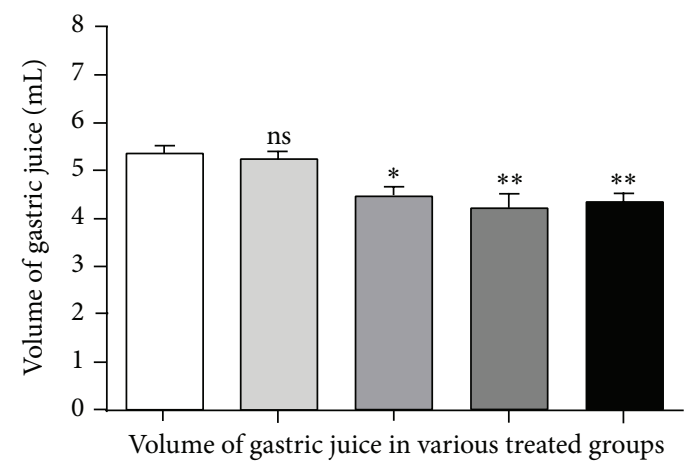

(a)

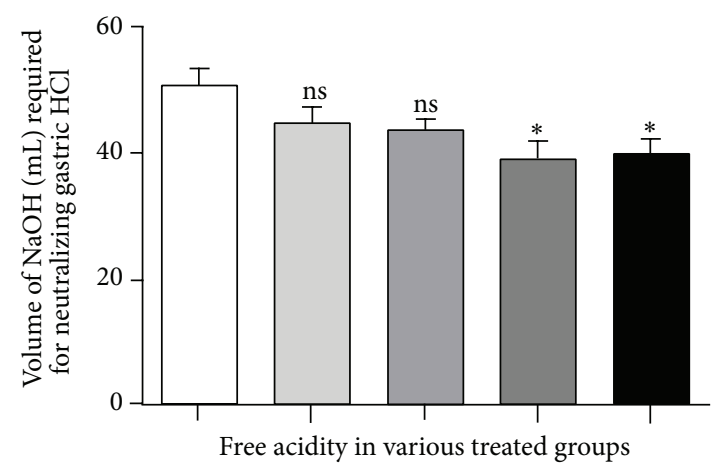

(c)

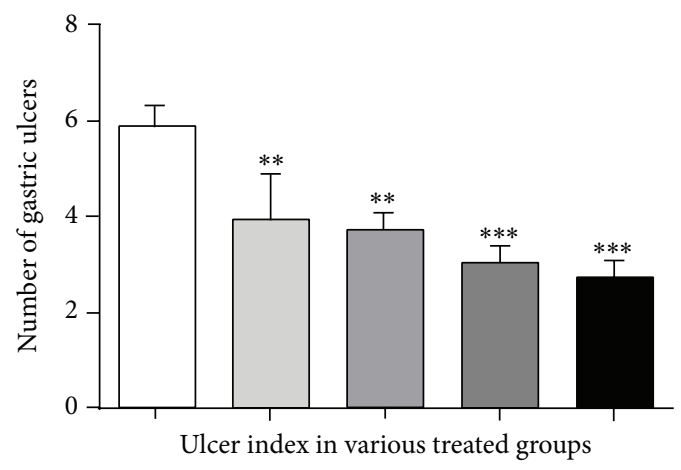

(e)

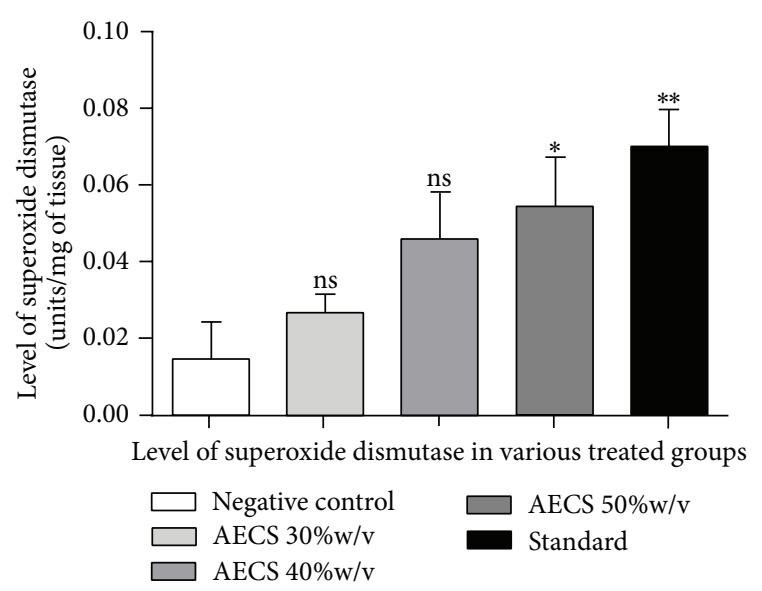

(g)

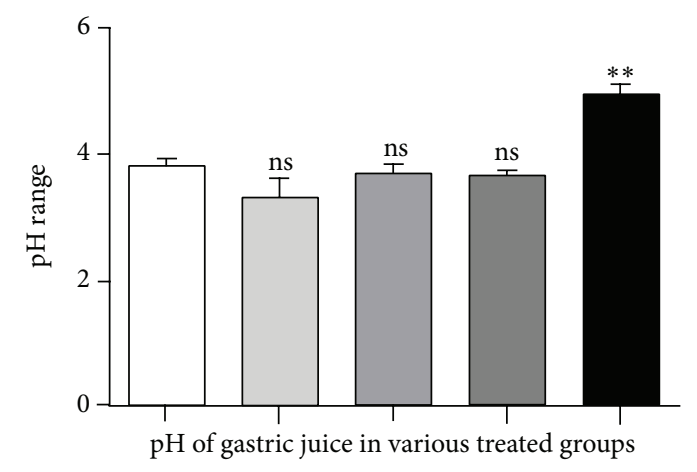

(b)

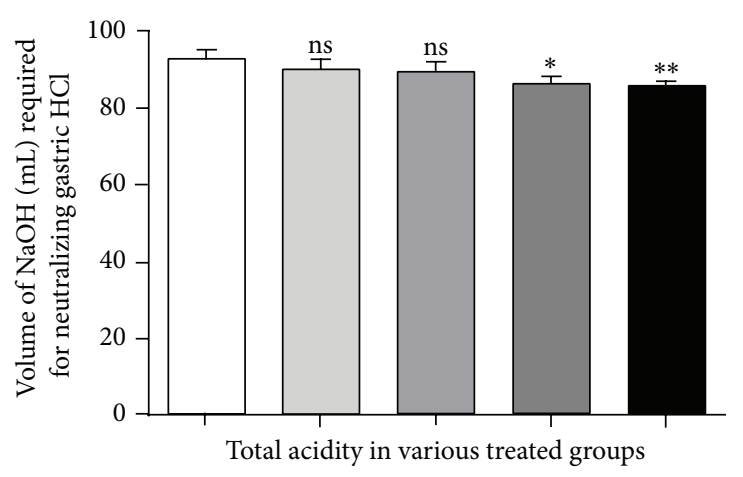

(d)

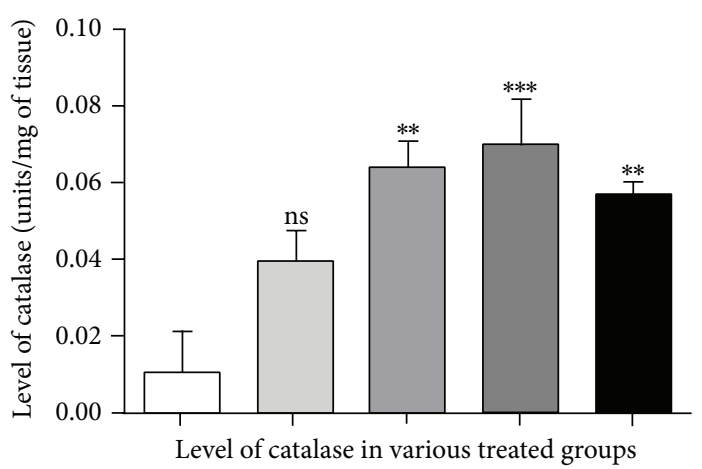

(f)

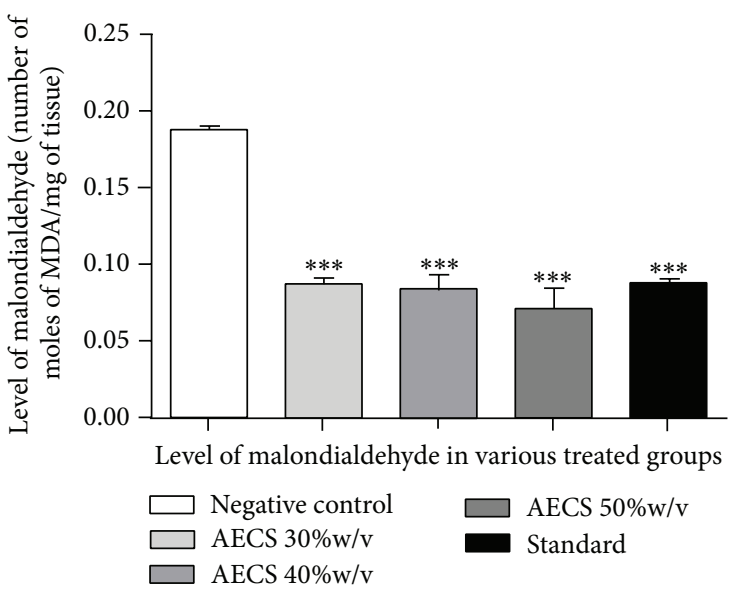

(h)

FIGURE 2: Graphs showing effect of AECS and standard drug on various gastric parameters. 
can be attributed to the essential amino acids and unsaturated fatty acids present in the extract. Further, this is the first study that highlights antioxidant potential of AECS in an in vivo experiment and indicates antioxidant activity as one of the probable mechanisms for the gastroprotective effect of AECS. It can be concluded that AECS possesses antisecretory and antiulcer properties, particularly at $40 \%$ and $50 \% \mathrm{w} / \mathrm{v}$ concentrations.

\section{Conflict of Interests}

The authors declare that there is no conflict of interests regarding the publication of this paper.

\section{Acknowledgment}

The authors acknowledge the facilities provided in carrying out the biochemical assays at the laboratory of Department of Pharmacology, College of Veterinary Science, Acharya N.G. Ranga Agricultural University, Rajendra Nagar, Hyderabad.

\section{References}

[1] A. M. Mat Jais, Y. M. Dambisya, and T. L. Lee, "Anti-nociceptive activity of Channa striatus (Haruan) extract in mice," Journal of Ethnopharmacology, vol. 57, pp. 125-130, 1997.

[2] K. Marimuthu and M. A. Haniffa, "Embryonic and larval development of the striped snakehead Channa striatus," Taiwania, vol. 52, no. 1, pp. 84-92, 2007.

[3] A. M. Mat Jais, R. McCulloch, and K. Croft, "Fatty acid and amino acid composition in Haruan as a potential role in wound healing," General Pharmacology, vol. 25, no. 5, pp. 947-950, 1994.

[4] A. M. Mat Jais, M. F. Matori, P. Kittakoop, and K. Sowanborirux, "Fatty acid compositions in mucus and roe of Haruan, Channa striatus, for wound healing," General Pharmacology, vol. 30, no. 4, pp. 561-563, 1998.

[5] A. Zuraini, M. N. Somchit, M. H. Solihah et al., "Fatty acid and amino acid composition of three local Malaysian Channa spp. fish," Food Chemistry, vol. 97, no. 4, pp. 674-678, 2006.

[6] M. A. Mohd Shafri and A. M. Mat Jais, "Therapeutic potential of the Haruan (Channa striatus): from food to medicinal uses," Malaysian Journal of Nutrition, vol. 18, no. 1, pp. 125-136, 2012.

[7] Z. A. Zakaria, M. R. Sulaiman, A. M. Mat Jais, and M. N. Somchit, "Effect of various antagonists on the Channa striatus fillet extract antinociception in mice," Canadian Journal of Physiology and Pharmacology, vol. 83, no. 7, pp. 635-642, 2005.

[8] Z. A. Zakaria, M. N. Somchit, M. R. Sulaiman, A. M. Mat Jais, and D. A. Israf, "Non-opioid antinociceptive activity of fresh Haruan (Channa striatus) fillet extract," Journal of Technology and Management, vol. 2, pp. 6-11, 2004.

[9] Z. A. Zakaria, G. H. Kumar, A. M. Mat Jais, M. R. Sulaiman, and M. N. Somchit, "Antinociceptive, antiinflammatory and antipyretic properties of Channa striatus fillet aqueous and lipid-based extracts in rats," Methods and Findings in Experimental and Clinical Pharmacology, vol. 30, no. 5, pp. 355-362, 2008.

[10] A. M. Saleem, M. T. Hidayat, A. M. Mat Jais et al., "Antidepressant-like effect of aqueous extract of Channa striatus fillet in mice models of depression," European Review for Medical and Pharmacological Sciences, vol. 15, no. 7, pp. 795-802, 2011.

[11] A. M. Saleem, M. Taufik Hidayat, A. M. Mat Jais et al., "Involvement of monoaminergic system in the antidepressantlike effect of aqueous extract of Channa striatus in mice," European Review for Medical and Pharmacological Sciences, vol. 17 , no. $15,2019$.

[12] M. N. Somchit, M. H. Solihah, D. A. Israf, Z. Ahmad, A. K. Arifah, and A. M. Mat Jais, "Anti-inflammatory activity of Channa striatus, Channa micropeltes and Channa lucius extracts: chronic inflammatory modulation," Journal of Oriental Pharmacy and Experimental Medicine, vol. 4, no. 2, pp. 91-94, 2004.

[13] A. M. Mat Jais, Z. A. Zakaria, A. Luo, and Y.X. Song, "Antifungal activity of Channa striatus (Haruan) crude extracts," International Journal of Tropical Medicine, vol. 3, no. 3, pp. 43-48, 2008.

[14] M. Dhanaraj, M. A. Haniffa, S. V. A. Singh, C. M. Ramakrishnan, D. Manikandaraja, and M. J. Milton, "Antibacterial activity of skin and intestinal mucus of five different freshwater fish species Viz., C. striates, C. micropeltes, C. marulius, C. Punctatus and C. gachua," Malaysian Journal of Science, vol. 28, no. 3, pp. 257-262, 2009.

[15] N. Y. T. Michelle, G. Shanthi, and M. Y. Loqman, "Effect of orally administered Channa striatus extracts against experimentallyinduced osteoarthritis in rabbits," International Journal of Applied Research and Veterinary Medicine, vol. 2, no. 3, pp. 171175, 2004.

[16] M. A. Mohd Shafri, A. M. Mat Jais, and M. K. Kyu, "Neuroregenerative properties of Haruan (Channa striatus spp.) traditional extract," Jurnal Intelek, vol. 6, no. 1, pp. 77-83, 2011.

[17] K. L. Wee, "Snakeheads: their biology and culture," in Recent Advances in Aquaculture, R. Muir and R. Roberts, Eds., pp. 181213, Westview, Press Boulder, 1982.

[18] S. H. Baie and K. A. Sheikh, "The wound healing properties of Channa striatus-cetrimide cream-tensile strength measurement," Journal of Ethnopharmacology, vol. 71, no. 1-2, pp. 93-100, 2000.

[19] S. H. Baie and K. A. Sheikh, "The wound healing properties of Channa striatus-cetrimide cream-wound contraction and glycosaminoglycan measurement," Journal of Ethnopharmacology, vol. 73, no. 1-2, pp. 15-30, 2000.

[20] R. K. Goel, A. Chakrabarti, and A. K. Sanyal, "The effect of biological variables on the anti-ulcerogenic effect of vegetable plantain banana," Planta Medica, vol. 2, pp. 85-88, 1985.

[21] N. Kannappan, S. Jaikumar, R. Manavalan, and A. K. Muthu, "Antiulcer activity of methanolic extract of Jatropha curcas (Linn.) on aspirin-induced gastric lesions in wistar rats," Pharmacologyonline, vol. 1, pp. 279-293, 2008.

[22] K. S. Asru, Handbook of Experimental Pharmacology, Vallabh Prakashan, New Delhi, India, 3rd edition, 1999.

[23] A. K. Sinha, "Colorimetric assay of catalase," Analytical Biochemistry, vol. 47, no. 2, pp. 389-394, 1972.

[24] M. Madesh and K. A. Balasubramanian, "Microtiter plate assay for superoxide dismutase using MTT reduction by superoxide," Indian Journal of Biochemistry and Biophysics, vol. 35, no. 3, pp. 184-188, 1998.

[25] K. A. Balasubramanian, M. Manohar, and V. I. Mathan, "An unidentified inhibitor of lipid peroxidation in intestinal mucosa," Biochimica et Biophysica Acta, vol. 962, no. 1, pp. 51-58, 1988. 
[26] J.-H. Chyun and P. Griminger, "Improvement of nitrogen retention by arginine and glycine supplementation and its relation to collagen synthesis in traumatized mature and aged rats," Journal of Nutrition, vol. 114, no. 9, pp. 1705-1715, 1984.

[27] C. K. Dahlan-Daud, A. M. Mat Jais, Z. Ahmad, A. Md Akim, and A. Adam, "Amino and fatty acid compositions in Haruan traditional extract (HTE)," Boletin Latinoamericano y del Caribe de Plantas Medicinales y Aromaticas, vol. 9, no. 5, pp. 414-429, 2010.

[28] L. H. Gam, C. Y. Leow, and S. Baie, "Amino acid composition of snakehead fish (Channa striatus) of various sizes obtained at different times of the year," Malaysian Journal of Pharmaceutical Sciences, vol. 3, no. 2, pp. 19-30, 2005.

[29] J. Schrager, "The composition and some structural features of the principal gastric glycoprotein," Digestion, vol. 2, no. 2, pp. 73-89, 1969.

[30] H. O. Hultin, "Lipid oxidation in fish muscle," in Advances in Sea Food Biochemistry, Composition and Quality, G. J. Flick and R. E. Martin, Eds., pp. 99-122, Technomic, Lancaster, Pennysylvania, 1992.

[31] Z. A. Zakaria, A. M. Mat Jais, Y. M. Goh, M. R. Sulaiman, and M. N. Somchit, "Amino acid and fatty acid composition of an aqueous extract of Channa striatus (Haruan) that exhibits antinociceptive activity," Clinical and Experimental Pharmacology and Physiology, vol. 34, no. 3, pp. 198-204, 2007.

[32] M. B. Witte, F. J. Thornton, U. Tantry, and A. Barbul, "Larginine supplementation enhances diabetic wound healing: involvement of the nitric oxide synthase and arginase pathways," Metabolism: Clinical and Experimental, vol. 51, no. 10, pp. 1269-1273, 2002.

[33] A. Barbul, "Arginine enhances wound healing and lymphocyte immune responses in humans," Surgery, vol. 108, no. 2, pp. 331337, 1990.

[34] J. Elsair, "Effect of arginine chlorhydrate on nitrogen balance during the three days following routine surgery in man," Biomedicine, vol. 29, no. 9-10, pp. 312-317, 1978.

[35] J. E. Albina, C. D. Mills, and W. L. Henry Jr., "Temporal expression of different pathways of 1-arginine metabolism in healing wounds," Journal of Immunology, vol. 144, no. 10, pp. 3877-3880, 1990.

[36] T. M. Devlin, Textbook of Biochemistry and Clinical Correlation, Wiley-Liss, New York, NY, USA, 1992.

[37] C. Salvatore, P. R. Dennis, P. C. Achille, and S. Daniela, "Approach in shock, inflammation and ischaemia/reperfusion injury," The American Society for Pharmacology and Experimental Therapeutics-Pharmacological Review, vol. 53, pp. 135-159, 2001.

[38] R. G. Ackman, "Nutritional composition of fats in seafoods," Progress in Food and Nutrition Science, vol. 13, no. 3-4, pp. 161241, 1989.

[39] M. P. A. Muntaziana, S. M. N. Amin, M. S. Kamarudin, and A. A. Rahim, "Effect of selected diets on the growth and survival of snakehead fish (Channa striatus) fry," Journal of Fisheries and Aquatic Sciences, vol. 2013, pp. 1-7, 2013.

[40] W. C. Bowman and M. J. Rand, Textbook of Pharmacology, Blackwell Science, London, UK, 2nd edition, 1980.

[41] B. G. Katzung, Basic and Clinical Pharmacology, Appleton and Lange, Stamford, Conn, USA, 6th edition, 1995.

[42] S. M. Huang, T. Bisogno, T. J. Petros et al., "Identification of a new class of molecules, the arachidonyl amino acids and characterization of one member that inhibits pain," The Journal of Biological Chemistry, vol. 276, no. 46, pp. 42639-42644, 2001.
[43] S. Westaby, Wound Healing, The Mac Millan Press, 2nd edition, 1985.

[44] A. M. Mohamed, Potential of antimicrobial activity of Channa striatus Bloch. (Haruan) fillet extracts [M.S. thesis], Universiti Putra Malaysia, 2012.

[45] O. Y. Wei, R. Xavier, and K. Marimuthu, "Screening of antibacterial activity of mucus extract of snakehead fish, Channa striatus (Bloch)," European Review for Medical and Pharmacological Sciences, vol. 14, no. 8, pp. 675-681, 2010. 

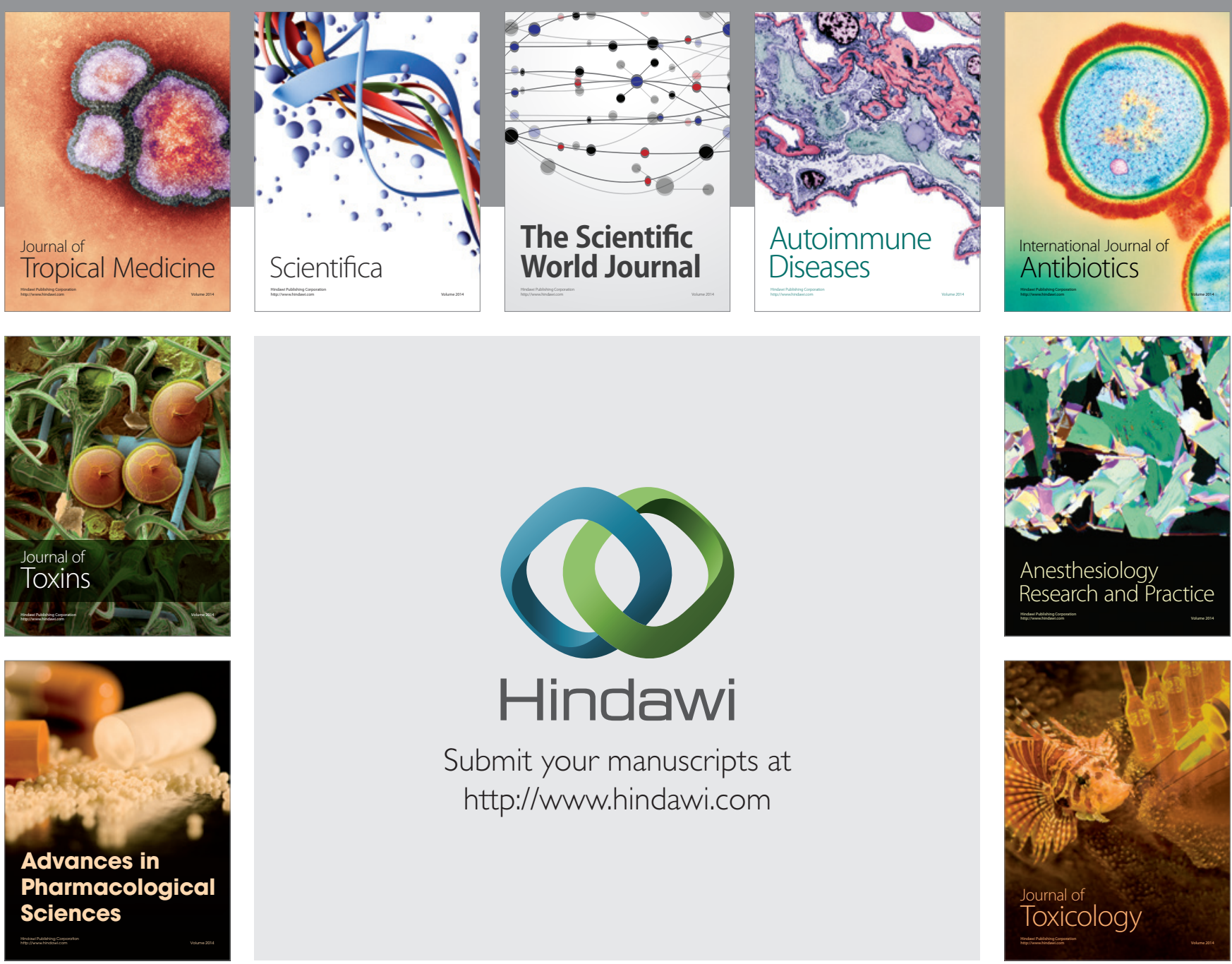

\section{Hindawi}

Submit your manuscripts at

http://www.hindawi.com
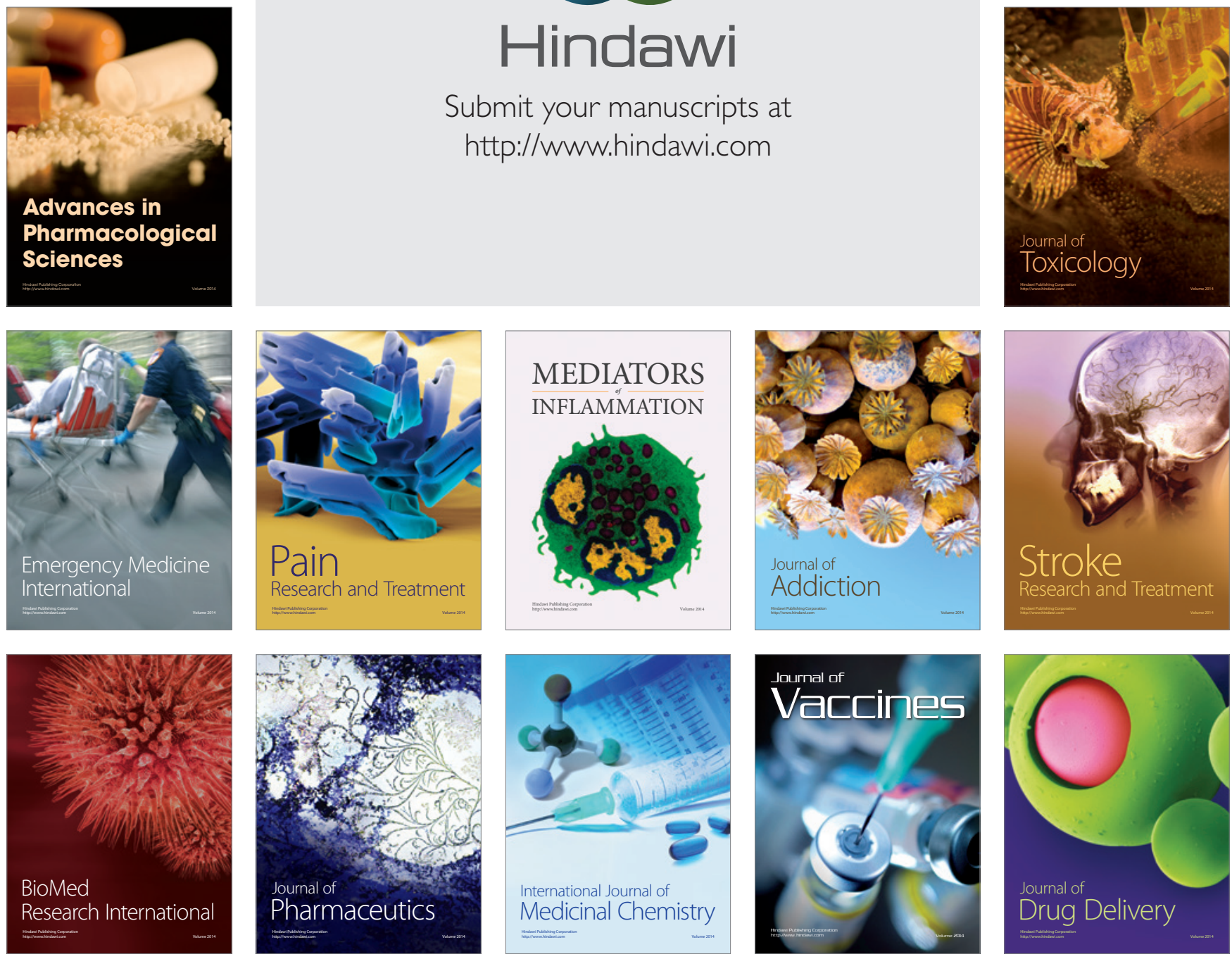